\title{
ENFermedad y POBREza en la Sierra de Chiapas
}

\author{
Eugenia Bayona Escat
}

Resumen: Este artículo indaga en la desigualdad y exclusión social que padece la población de la región Sierra, Chiapas, en el ámbito de la salud. Se aborda desde los testimonios de mujeres rurales que ofrecen su propia visión de la salud, la enfermedad y la atención sanitaria, y desarrollan diferentes estrategias para afrontar las dificultades. Se pretende demostrar cómo en un medio adverso, caracterizado por la pobreza y olvido institucional, los trastornos fisicos son reiterativos, se convierten en incurables y contribuyen a la reproducción de la marginalidad. Así, se genera la enfermedad de la pobreza, que somatiza males físicos para expresar las carencias sociales.

Palabras clave: Sierra de Chiapas, pobreza, marginación social, enfermedad de la pobreza

Enviado a dictamen: 19 de agosto de 2011 Aprobación: 21 de octubre de 2011 Revisiones: 1

Dra. Eugenia Bayona Escat, profesora ayudante, doctora en la Universidad de Valencia. Doctora en Ciencias Sociales, especialidad Antropología Social y Cultural. Centro de Investigaciones y Estudios Superiores en Antropología Social, Unidad Occidente, Guadalajara. Temas de especialización: migración, pobreza y género. Correo electrónico: m.eugenia.bayona@uv.es.
Abstrac: This article explores the inequality and social exclusion that it suffers from the population of the region Sierra, Chiapas, in the field of health. Addressed from the testimonies of rural women who offer their own vision of health, disease and health care, and develop different strategies for dealing with the difficulties. It is intended to demonstrate how in an adverse environment, characterized by poverty and institutional neglect, physical disorders are repeatable, become incurable and they contribute to the reproduction of marginality. Thus arises the disease of the poverty, which somatizes physical ills to express social deprivation.

Keywords: Chiapas's Sierra, poverty, social marginalization, disease of the poverty.

\section{Introducción}

E ste artículo trata sobre los altos riesgos de enfermar y morir que tienen los habitantes que viven en una de las regiones más olvidadas de Chiapas, la Sierra, que comparte con otras regiones del estado de Chiapas los índices más elevados de pobreza y marginación social del país. ${ }^{1}$ El trabajo se centra en los testimonios de mujeres rurales que relatan sus experiencias sobre padecimientos, tratamientos y el limitado acceso a los sistemas de salud en la región. El 
tema aborda la salud-enfermedad entre la población rural con causas que se asocian a la pobreza, al medio físico o a un aislamiento geográfico pero también social, que provocan múltiples consecuencias. Interesa comprender cómo se manifiestan la desigualdad y la exclusión social en el ámbito de la salud, en un contexto idóneo para el análisis caracterizado por el aumento y reiteración de enfermedades y muertes entre una población que vive en la miseria, sobrevive de lo poco que da la tierra y habita en comunidades pequeñas, en las laderas de las montañas o en lugares que dificultan su conexión con otros centros urbanos. Se habla de la enfermedad de la pobreza, para diferenciar un tipo de mal físico que se convierte en social, que refleja todo tipo de carencias económicas y sociales, y demuestra las contradicciones de vivir en un contexto de mayor vulnerabilidad social.

La Sierra es una de las regiones de Chiapas más pequeñas, con $2.8 \%$ de superficie estatal, y cuenta con ocho municipios con índices que oscilan entre alta y muy alta marginación. ${ }^{2}$ En el año 2005, la población total de la región suma un total de 169,896 habitantes, y se distribuye en 876 localidades, de las cuales $98.2 \%$ no superan los 1,000 habitantes (INEGI; 2005). La región, además, tiene una topografía accidentada, con alturas que van desde los 870 metros sobre el nivel del mar en las tierras bajas hasta 2,850 en las zonas altas, con un índice elevado de precipitaciones anuales, lo que la convierte en una zona considerada de alto riesgo, con inundaciones, vientos, tormentas eléctricas y huracanes (COESPO, 2002). ${ }^{3}$ La mayoría de la población reside en localidades pequeñas y dispersas, con vías de comunicación deficientes, mal acondicionadas o de tierra, que quedan inutilizadas en temporada de lluvias y por continuos derrumbes. La actividad económica más importante es la agricultura, representada por $73.6 \%$ de la población, que subiste con el cultivo de los escasos productos agrícolas (maíz y fríjol mayoritariamente, así como papa y algunas hortalizas), con la venta informal de algunos alimentos y los trabajos eventuales que consiguen los hombres como jornaleros o asalariados. Sólo 10\% de la población de toda la región reside en la capital de Motozintla, que posee los servicios políticos y administrativos más importantes, incluido el hospital y otros servicios de salud especializados (INEGI; 2000). Los datos del Consejo Nacional de Población (CONAPO $)^{4}$ revelan que la población tiene carencias en la mayoría de indicadores: bajo nivel educativo y alto analfabetismo, reducidos o nulos ingresos y una población distribuida en pequeñas localidades que reside en viviendas sin servicios básicos de agua, luz o drenaje. ${ }^{5}$ La pobreza y marginación se expresan también en otros indicadores con la reducida inversión estatal productiva en la región, una deficiente infraestructura pública en educación, comunicaciones internas, en instalaciones telefónicas y otras señales de transmisión, y un sistema de salud inexistente, sin suministros ni atención médica, que provoca índices elevados de mortalidad infantil y materna.

Este trabajo forma parte de una investigación más amplia que se ha realizado en todo el estado para analizar los efectos de la crisis global entre la población femenina rural. ${ }^{6}$ En la Sierra, los resultados del proyecto confirmaron que la crisis ha repercutido negativamente en la situación económica de las familias campesinas, que han pasado de una permanente pobreza e inestabilidad económica a índices alarmantes de extrema pobreza. La crisis ha agudizado una situación insostenible en el campo con familias campesinas que tienen escasos ingresos, sobreviven de los cultivos en tierras erosionadas y de baja productividad, que ya no dan lo suficiente para la subsistencia familiar, sin apoyo estatal ni inversión en producción ni tecnología, y que ahora enfrentan una subida en el precio de los alimentos básicos, lo que ha desequilibrado por completo la precaria economía familiar (Villafuerte y García, 2004, 2006, 2008). Los agricultores pobres, sin recursos ni capacitación para entrar en otros ámbitos laborales, se han visto obligados a reducir el consumo de algunos alimentos y a sobrevivir con préstamos y 
deudas para poder comprar los suministros necesarios para el consumo familiar. Además, esta situación ha repercutido negativamente entre las mujeres, en un contexto asimétrico de género que ahora se ha intensificado por los efectos de la crisis y ha provocado una mayor desigualdad y marginación social femenina. La desigualdad de género se refleja en mujeres que asumen doble carga de trabajo dentro y fuera del hogar para conseguir ingresos extras, se encargan de la manutención doméstica y familiar, velan por la salud de todos los miembros, alargan su etapa reproductiva con embarazos continuos y asumen riesgos innecesarios en la etapa de gestación, lo que repercute en un acelerado y permanente deterioro de su salud.

La experiencia de estas mujeres nos acerca a una vivencia cotidiana familiar de enfermedades, muertes, accidentes y riesgos innecesarios. Predominan sus voces explicando las causas y consecuencias de los padecimientos, las estrategias que utilizan y a quién culpabilizan de su situación -a la pobreza, al medio ambiente, a la contaminación, al consumo de productos industriales o a las políticas públicas, entre otros factores. ${ }^{7}$ El perfil de la muestra corresponde a mujeres en edades comprendidas entre 16 y 65 años o más, con niveles bajos de escolaridad, algunas de las cuales son analfabetas y otras que saben leer y escribir a nivel de primaria, y que se dedican mayoritariamente al trabajo doméstico y familiar. ${ }^{8}$ Viven en residencias de una sola planta, con una o dos habitaciones y con pocos muebles: algunas sillas, mesas, camas y estantes para colocar los utensilios domésticos. Cocinan en hornos de leña y tienen pocos aparatos eléctricos: alguna radio, televisores, frigoríficos y muy pocos celulares. Los materiales utilizados para la construcción son muy precarios: paredes de adobe, tablas, o incluso lámina de cartón, pisos de tierra o de cemento, y techos de lámina de metal, cartón o madera. Poseen electricidad, pero carecen de drenaje $y$ de agua entubada en el solar, y edifican letrinas fuera de las casas, al aire libre y sin agua corriente. ${ }^{9}$
La gran mayoría conforma familias nucleares de parejas casadas o en unión libre con un promedio de 5 a 8 hijos. Profesan una gran variedad de religiones: católica en su mayoría, pero también presbiteriana, Adventistas del Séptimo Día, pentecostales o testigos de Jehová. ${ }^{10}$ El cabeza de la familia es el esposo que toma las decisiones importantes en el hogar y decide sobre los gastos y la participación social de otros miembros. Los padres e hijos varones se dedican a las tareas agrícolas, aunque algunos trabajan como jornaleros o consiguen otros empleos temporales o informales. ${ }^{11}$ Las madres e hijas en el hogar dedican jornadas completas de 8 a 14 horas, entre el cuidado de los hijos y el hogar, la compra y preparación de alimentos, lavado de ropa, tareas del campo y cuidado de animales, además de algunas tareas extradomésticas que realizan para la contribución económica familiar. Los ingresos de una familia son tan escasos que la migración de algunos de los miembros familiares ha sido la estrategia más recurrente para conseguir los necesarios recursos para la subsistencia. La migración ahora se realiza hacia el norte del país y hacia Estados Unidos, y el flujo migratorio está compuesto tanto por hombres como mujeres de distintas edades, aunque en la última década ha crecido la participación migratoria de los jóvenes de ambos sexos. La migración no ha resultado ser la opción más adecuada para combatir la miseria actual de las familias, porque la inexperiencia migratoria, los gastos del viaje y la falta de redes eficaces convierten al viaje en un trayecto difícil y a veces sin retorno. Además, muchos de los que traspasan la frontera prefieren quedarse allá y se olvidan de los suyos, mientras los que vuelven invierten todas sus ganancias en objetos materiales y de prestigio social para de nuevo volver a emprender la marcha. La migración, más que una solución, se está convirtiendo en un estilo de vida para escapar de la pobreza y miseria del campo.

En estos contextos de pobreza y marginación social, la enfermedad y los riesgos de muerte son temas 
recurrentes entre las mujeres, que se expresan a través de la preocupación e incertidumbre en numerosos ámbitos: temor a los partos, a enfermedades que se convierten en crónicas, a padecimientos asociados con el medio hostil en el que viven, a la desnutrición de sus hijos y a otros malestares en el cuerpo que reflejan las graves carencias de la población. Las mujeres hablan también de la falta de atención médica adecuada, de errores médicos, carreteras en mal estado, ausencia de trasporte público, lo que impide llegar a tiempo a la clínica u hospital para salvar la vida de muchas personas, con la consecuencia más común: quedarse alrededor de los suyos para esperar la muerte. El aislamiento geográfico y social de la Sierra se convierte en un contexto propicio para la aparición y reproducción de todo tipo de enfermedades que, para quienes las padecen, se convierten en un círculo sin posibilidad de salida, con dependencia en medicinas, en largos tratamientos y en dolencias incurables.

\section{La enfermedad de la pobreza}

La pobreza es una condición social que se construye desde la desigualdad e implica escasez económica y limitado acceso a los recursos, pero también privación y restricción en muchos otros ámbitos sociales. Los pobres se caracterizan por tener bajos ingresos económicos y vivir en un contexto de exclusión social al margen de una educación y atención sanitaria adecuada, sin capacitación laboral y ante la imposibilidad de encontrar empleos mejores remunerados; sin adecuados suministros de agua, luz, comunicaciones y trasportes, y en ausencia de oportunidades o alternativas viables para salir de esta situación. Vivir en un contexto de marginación y pobreza no significa estar al margen, sino sobrevivir con base en trabajos esporádicos, oficios mal pagados, economía informal y una combinación de estrategias parentales, familiares y vecinales que se desarrollan para enfrentar las carencias (Lomnitz, 1985, González de la Rocha, 1986). La pobreza forma parte de una estructura jerárquica y desigual de estratos sociales en donde los pobres se sitúan en las escalas más bajas porque tienen a su alrededor barreras físicas y sociales que reproducen continuamente su marginalidad.

En el campo de la salud, esta pobreza y marginación social se traduce en tener tasas más altas de mortalidad, menos expectativas de vida y sufrir enfermedades que son evitables y curables en otros contextos. Las condiciones de vida en las que viven los pobres los expone a todo tipo de enfermedades que surgen de las carestías de alimentación y de espacios sin salubridad: aguas estancadas, sucias o contaminadas, inexistencia de drenajes, falta de infraestructura adecuada para la recogida de basuras o alimentos en mal estado, entre otros factores. También, su vulnerabilidad se expresa en la imposibilidad de tener recursos económicos suficientes para enfrentar una enfermedad y la incapacidad de solventar los gastos que se requieren para una posible curación, con padecimientos, en muchos casos, evitables y curables, que se convierten en enfermedades crónicas o en fallecimientos imprevistos. La desigualdad también se visibiliza en el negado acceso a los servicios sanitarios públicos debido a la ausencia de hospitales o su ubicación a horas de traslado; en la falta de personal capacitado de asistencia o en su sustitución, en muchos casos, por asistentes sin las habilidades suficientes para tratar urgencias médicas; o bien, en la inexistencia de un trasporte público o sanitario adecuado, lo que imposibilita trasladar y atender a los pacientes en caso de riesgo. La pobreza, en el campo de la salud, se asocia directamente a enfermedad y mortalidad, y expone a la población a un mayor riesgo, sobre todo en determinadas etapas generacionales: mortalidad fetal, infantil y materna, como los ejemplos más característicos.

En este trabajo se habla de la enfermedad de la pobreza como un flagelo que va más allá de aspectos biológicos para caracterizarse como expresión de una desigualdad social. La enfermedad de la pobreza 
aparece entre la población que vive en un medio hostil y sin recursos para combatir los riesgos que provoca un entorno de marginación social. Se trata de una enfermedad social que se somatiza en males físicos, porque muchas de sus causas se relacionan con la privación y sus consecuencias pueden derivar en una mayor pobreza, abandono y aislamiento social. Además, la enfermedad de la pobreza se caracteriza porque es incurable; mientras en otros lugares el mal es tratable, bajo estas circunstancias los tratamientos son más largos y en muchos casos permanentes, lo que provoca una constante reproducción de la situación de escasez económica y marginalidad asociada. La enfermedad de la pobreza también hace alusión a un tratamiento médico desigual, sin posibilidad de acceder a buenos médicos, tratamientos u operaciones, y con escasas posibilidades de negociación.

En este trabajo, los conceptos de salud y enfermedad están comprendidos como procesos sociales que ocurren y se desarrollan dentro de un contexto específico. Siguiendo a Eduardo Menéndez (2003, 2005a), es necesario atender al proceso de salud, enfermedad y atención sanitaria en conjunto, como hechos sociales recurrentes e inevitables que afectan a la vida cotidiana de los grupos sociales. Por un lado, este análisis remite a las prácticas y representaciones que se hacen en torno a la salud, a la enfermedad y a los cuidados y atención que se ofrecen para enfrentar los padecimientos, pero también se relaciona con aspectos económicos, sociales y políticos que influyen en las condiciones de vida de las personas y las exponen a mayores riesgos en su salud. Asimismo, el hecho de reconocer a la población rural como más vulnerable en el ámbito salud-enfermedad, focaliza el problema en los aspectos socioeconómicos, más que en conductas de riesgo individuales, y permite analizar el desarrollo de todo tipo de malestares físicos como expresiones de una diferenciación social (Brofman et al, 2001)..12 De esta forma, ver el proceso en conjunto permite observar cómo operan las desigualdades sociales y qué mecanismo de exclusión social aparecen en cada una de las fases.

Además, propongo analizar la enfermedad como un proceso sociocultural en el que determinadas manifestaciones se convierten en diagnósticos de padecimientos clínicos para el modelo hegemónico médico, que en este contexto resultan ineficaces para combatir las desigualdades sociales (Menéndez, 2003, 2005b)..$^{13}$ En este sentido, Scheper-Hughes (1997) plantea cómo las instituciones médicas resuelven las enfermedades desde una perspectiva individual —con casos clínicos que requieren medicinas y otros tratamientos-, pero que oculta los problemas mayores de males sociales asociados a un entorno de pobreza estructural y marginación social. En otras palabras, para el modelo médico hegemónico, la enfermedad individual se cura con medicinas, pero la enfermedad de la pobreza, la del hambre y de la carestía son problemas de Estado, con repercusiones políticas sin fácil solución. Por eso, una de las características de la enfermedad de la pobreza es su reincidencia, a pesar de ser tratada y diagnosticada como un mal individual, porque aparecen continuas complicaciones de salud, que se diagnostican, reciben tratamientos y vuelven a aparecer. Son los males sociales de cuerpos que somatizan enfermedades, e incluso muertes, como consecuencia directa de un entorno periférico y marginal.

Por otro lado, la atención sanitaria deficiente en la región se sustituye con los cuidados familiares que recaen, en la mayoría de los casos, bajo responsabilidad de las mujeres, quienes dedican tiempo y esfuerzo a la curación del enfermo. La familia se convierte en una ayuda indispensable para el enfermo, que requiere de cuidados, protección y gastos familiares para salir adelante. Las estrategias que involucran la curación van desde remedios caseros hasta largos tratamientos que desequilibran la precaria economía familiar, y obligan a pedir préstamos para hacer frente a la enfermedad. En la Sierra, mujeres y hombres de distintas edades se socializan en un ambiente familiar caracterizado por 
continuas complicaciones en la salud de alguno de sus miembros. La socialización a través de la enfermedad implica que los padecimientos reiterativos terminan por convertirse en algo normal y cotidiano dentro de la dinámica familiar y la enfermedad se naturaliza como una característica más de los riesgos que comporta la vida diaria. Así, las causas de los males oscilan entre riesgos ambientales, alimentarios y hábitos cotidianos, y las prácticas de curación se desarrollan dentro de una economía escasa que utiliza todo tipo de conocimientos y remedios prácticos y diferentes redes de apoyo familiares y vecinales.

Muchas de las complicaciones en la salud de las familias campesinas son una respuesta inmediata a las condiciones precarias en las que viven. Son factores sociales que remiten a una violencia estructural que afecta a la población sin recursos, la más vulnerable por vivir al margen de apoyos estatales y una atención sanitaria eficiente. La violencia estructural se encuentra estrechamente vinculada con la desigualdad social y forma parte de la estructura que impide a un sector de la sociedad cubrir las necesidades básicas: ingresos, desempleo, educación, vivienda, alimentación o servicios sanitarios entre otros. No se trata de una violencia directa, sino que remite a una estructura de dominación y asimetría con base en la explotación laboral, la repartición desigual de recursos y la limitación de actuación. (Farrona, 2006; Galtung, 1981; Spitz, 1981). En el caso de la Sierra se trata de una violencia estructural institucionalizada que priva a las personas de los derechos básicos y provoca riesgos innecesarios y muertes sin sentido (Freyermunt, 2011). Aquí se va a hablar de un sector pobre que se caracteriza por vivir con carencias en un entorno de privación, que somatiza males sociales a través de enfermedades individuales, y que utiliza el cuerpo como un último recurso para simbolizar la exclusión y la desigualdad social en la que está inmerso (Goldberg, 2010, Scheper-Hughes, 1997).

\section{Los males del mundo moderno}

La mayoría de enfermedades crónicas que padecen los habitantes en la Sierra son generadas por el aislamiento geográfico y social en el que viven. Los testimonios hablan de preocupaciones por el aumento de nuevas enfermedades, con causas asociadas al medio físico, como el agua contaminada, la tierra poco productiva, el alimento sin nutrientes, el frío, las lluvias eléctricas o los huracanes que provocan catástrofes irreparables. La enfermedad de la pobreza tiene múltiples causas asociadas que se combinan para explicar las consecuencias:
Mire todo este cerro: iqué vamos a producir ahí?, y así hay gente que nada más vive de su poquito de maíz, y si está bueno el tiempo va a haber buena temporada. Si no llueve normal, no va a haber buena temporada de maíz, y se queda uno viviendo con la necesidad (...) ¿Por qué nos morimos tanta gente pobre? Porque no alcanzamos para la comida. Imagínese cómo está el tiempo; ahora vamos por allá por la Sierra, vamos a darnos cuenta cuántos niños hay descalzos en la lluvia, casi desnudos, porque no alcanza el dinero (...) ¿Por qué se enfermó de esto, o por qué no está capacitado para la escuela? Porque no sabe tomar un vaso de leche al día, no te sabe comer un pedacito de queso tan siquiera, no hay nada, no alcanza el dinero.

Para muchas mujeres el origen de las desgracias radica en los males del mundo moderno que provocan un desequilibro en la naturaleza y enfermedades anteriormente inexistentes: "Pues, ahorita por la naturaleza, hay muchas enfermedades más que nada está critico y viene más crítico todavía”. Hay quienes comentan que la situación se agrava en la temporada de lluvias, con las heladas y el frío de la montaña:

Pues a veces que sufren los niños de diarrea y vómito y a veces no sabemos, pero les sube mucha roncha; 
creo yo es por el agua, por el agua, y aquí hay mucho mosquito.

También, por la erosión de la tierra, el poco maíz que se produce, las verduras contaminadas por los fertilizantes y químicos, o por las aguas sin purificar que beben o utilizan para regar las cosechas:

Ya las cosas que se comen aquí ya no son naturales; hay mucho abono, todo artificial, y las verduras, todo regado con aguas negras, y vamos a durar menos.

Los efectos de la migración en la región también han provocado otros hábitos de consumo anteriormente inexistentes que han afectado la salud de muchas personas. Las remesas que se reciben se utilizan, entre otros gastos importantes, para comprar la comida y las medicinas necesarias, así como para acudir a un doctor particular, pero también hay dinero que se malgasta en comprar bebidas y comidas industriales. Se consumen bebidas, jugos embotellados, bolsas de papas y doritos, y golosinas que tienen mucha azúcar y no son tan buenas como el pozol, el atole y los aguas de frutas naturales:

Ha traído muchas consecuencias esto de la migración. Si el hombre le envía dinero a la mujer mensual, llega el consumismo en la familia. Ahora ya va todo enlatado, ya es pura Fanta, Coca o Big Cola, y no decimos "voy a hacer mi pozol", "voy a hacer mi agua de limón", "voy a hacer mi agua de frutas" (...) Ese es problema pues que está afrontando la población; de hecho más las mujeres, porque somos las que más nos enfermamos, más aptas a todo este tipo de contaminación.

Además, algunos de los jóvenes que han migrado vuelven a sus hogares con nuevos vicios como las drogas y el alcohol, lo que repercute en su salud y también en la de sus familiares, porque las preocupaciones de los hijos las pagan los padres.
Pero las mujeres también atribuyen las enfermedades a una situación económica insostenible: la pobreza, que no sólo es la causante de no poder comprar los alimentos básicos, sino que además impide adquirir las medicinas necesarias y pagar a un buen doctor, convirtiendo a los enfermos en crónicos e incurables. En cierta forma, la pobreza para las mujeres es una enfermedad permanente que no tiene rápida solución. No se puede curar con medicinas, ni se puede tratar como un síntoma aislado, y es una situación que ha empeorado en los últimos años provocando miedo e incertidumbre ante el futuro. La pobreza impide la curación y, quizás por eso, en la Sierra se dice que la enfermedad es el peor mal y que lo único que se necesita es seguir sano, porque sin dinero no hay tratamiento posible.

\section{La carestía de alimentos}

Si un tema preocupa constantemente entre las mujeres es la subida del precio de los alimentos, pues provoca una reducción de los suministros básicos para cocinar y es una de las primeras señales de una carestía que puede derivar en hambre. Enfermar de hambre no es algo que la gente hable abiertamente, sino que se expresa por otras vías: en el alza de precios, que ya no permite comprar tantos enseres, así como en la poca variedad en la dieta y en el racionamiento que debe efectuarse diariamente para que toda la familia pueda alimentarse. La carestía provoca que se hayan reducido las cantidades y la variación de los alimentos. Se come frijol y maíz como el alimento básico y se combina con algunas papas, pasta y huevos, mientras la carne, los lácteos y derivados, la fruta y algunas verduras, han desaparecido casi por completo de la dieta familiar..$^{14}$ El pollo es el único animal que se cocina una o dos veces por semana y se hacen, por ejemplo, grandes cacerolas de caldo para que pueda ser consumido y llegue para todos. Tiene que ser pollo de rancho porque, como dicen las mujeres, el de las ciudades "no tiene el mismo sabor y no alimenta lo suficiente". En cambio, en el campo el pollo es "más 
bueno", porque es más gordo, se saca más carne y el caldo es más espeso. Esta dieta escasa y repetitiva, sin los nutrientes necesarios, provoca una desnutrición severa y deriva en anemia y en otras enfermedades asociadas. ${ }^{15}$

En la Sierra, es más probable que las conversaciones de las mujeres giren en torno a la carestía que en torno al hambre, aunque la desnutrición se visibiliza en sus caras afiladas, en los dientes negros y en el cansancio continuo que padecen. Es un hambre acumulada desde la infancia que se reproduce diariamente en el interior de los hogares y con el que se vive cotidianamente. Para algunas mujeres la pobreza es una situación constante, como una prueba de sufrimiento que Dios ha puesto en el camino para poderla combatir con fuerza, aguante y paciencia. No hay suficiente porque el esposo no encuentra trabajo, no llega nada de dinero a la casa, el campo ya no produce y ha subido todo de precio. Las mujeres intentan vender animales o algún producto agrícola (verduras, huevos, pollos o cerdos), preparan comidas (pan, atole, tamales) o lavan la ropa. Pero, como ellas afirman: “idónde vamos a vender si todo el mundo anda igual?”. Así, en los últimos años, ha empeorado la situación de pobreza hasta llegar a la de miseria, y ya no alcanza ni para tener diez pesos para el gasto diario:

Yo antes a la semana me compraba un cono de huevo, pues ahora sólo me alcanza para medio cono. Antes yo podía comprarme un kilo o dos kilos de frijol; ahora ya me limito hasta de comer mis frijoles. ${ }^{16}$

Las madres se encargan de organizan las comidas diarias y tienen que procurar que todos sus hijos coman diariamente, lo que las convierte en las responsables de la administración y repartición del consumo diario. Ellas son las que preparan el alimento en fogones de leña, las que calientan la comida mientras el marido y los hijos comen, y las que se quedan las últimas para comer los restos que han quedado. La ansiedad, lo nervios y otros malestares del cuerpo aparecen en mujeres que trabajan más de una jornada diaria, que duermen poco, que se dedican a las tarea del hogar y a la vez preparan tamales, tortillas, jugos, comida para vender, cocinan, limpian la ropa y la casa y deben cuidar que todos sus familiares tengan, al menos, un plato de comida en la mesa. Son los males invisibles del cansancio y del sufrimiento que deben ser cargados en silencio para que la familia siga adelante. Como comenta Scheper-Hughes (1997), los nervios y otras dolencias reflejan la expresión que adopta el cuerpo para manifestar su inconformidad ante el hambre y las perturbaciones que conlleva. En la Sierra las expresiones de estos nervios entre las mujeres tienen que ver con manifestaciones de caída de cabello, calambres, ansiedad, dolor en el pecho y otros síntomas provocados por las preocupaciones que no dejan dormir tranquilamente:

Quién sabe por qué como yo vivía allá en las tablas y como se murió mi esposo, me enfermé, se acabó de caer todo mi cabello, todo. Después me fui a México casi dos años, creo. Me fui a curarme a México. Si, todo mi cabello, todo este pedazo, todo nomás un poquito quedó aquí. Llegando allá, como tengo una mi hermana allá, me dijeron "la vamos a curar tía", "vamos a comprar su tratamiento" (...) Muy difícil, porque yo decía "que se acabe de caer todo"; si yo me muero, imis hijos qué van a hacer? Chiquitos estaban todavía. Los dejé aquí con mi mamá. Gracias a mi mamá ella los cuidó un tiempo y por eso me pude recuperar y ahorita ellos me ayudan, ya no es tanto como los años pasados, porque los años pasados cuando ellos estaban chiquitos, estaba muy duro.

\section{Medicinas y enfermedades}

Una de las causas principales del aumento de enfermedades para las instituciones médicas es el medio físico de la Sierra, que provoca problemas gastrointestinales y respiratorias que derivan en diarreas, vómitos, pulmonías y gripes. ${ }^{17}$ También hablan de enfermedades asociadas a parásitos, y 
las endémicas como el dengue y, sobre todo, la oncocercosis, ${ }^{18}$ que se trasladó desde el Soconusco a la Sierra junto los trabajadores cafetaleros y se aposentó en las plantaciones de café en la región. Pero los testimonios de las mujeres hablan de repetidas complicaciones de salud, sobre todo entre mujeres, niños y ancianos: las diarreas y calenturas, las irritaciones en la piel, la subida del azúcar, los ojos cansados, los partos prematuros o complicados, la diabetes que ha aumentado en los últimos años, el colesterol, el cáncer de ovarios, o los infartos, que todos temen. Entre todos ellos, los niños son los que más preocupan porque están delgados, comen poco, les duele "la tripa" y les sube la fiebre:

Aquí hay mucha gripa, infecciones de la piel y la diarrea. No se por qué la diarrea, siento que es la mala nutrición, la tortilla y el café, y por la temperatura, porque a veces andan descalzos y porque andan jugando agua, o porque se están bañando con agua fría, porque aquí la mayoría se baña con agua fría, no tienen mucha leña para estar calentando.

La pobreza se refleja en esta mayor propensión a sufrir enfermedades y en una consecuente dependencia en medicamentos y tratamientos asociados como pastillas, jarabes, inyecciones o ampolletas que remedian dolencias que son diagnosticadas por los médicos como enfermedades aisladas. ${ }^{19}$ Para las instituciones sanitarias, las enfermedades que tienen que ver con la carestía se traducen en una mala alimentación familiar, la desnutrición, en descuido de las madres, los nervios y los dolores de cabeza se curan con tranquilizantes, la diabetes es síntoma de una dieta desequilibrada, el cansancio se remedia con vitaminas y las diarreas con antiparásitos, suero y antibióticos. Los remedios a todos los males se tratan con medicinas que son caras, pero se compran porque pueden ayudar a aliviar los síntomas y combaten los males. Pero las medicinas no suelen ser la solución, sino una forma de paliar el dolor y el mal pasajero que vuelve a repetirse después de un tiempo. Además, ninguna de ellas ha resultado eficaz para erradicar la enfermedad de la pobreza.

Las enfermedades de ancianos, adultos o niños dejan a la familia en una situación de vulnerabilidad económica y la exponen a un desequilibro económico. Para solventar el gasto, se pide dinero prestado a familiares o vecinos, se fían los alimentos en las tiendas y se buscan recursos fuera de la región, con la necesaria migración de algunos de sus miembros, que envían dinero para enfrentar estas situaciones críticas. Algunos de los migrantes han preferido quedarse en los lugares de destino y no mandar más dinero a sus familiares, lo que ha comportado un aumento de familias matrifocales de madre e hijos que tienen grandes dificultades para salir adelante. La posibilidad de enfrentar estos gastos de enfermedad en el núcleo familiar, siempre dependerá de los recursos que toda la familia puede reunir para enfrentar estas situaciones. Los núcleos familiares con pocos miembros son más vulnerables a acumular deudas y a tener que extender sus círculos de ayuda para solventar el gasto. En muchos casos no pueden conseguir el suficiente dinero y el enfermo no se cura por falta de medicinas. Además, se disminuye el gasto en otros recursos, como la alimentación, que es necesaria para combatir la debilidad que provoca el malestar físico. Así, la pobreza se reproduce constantemente en un contexto de clara relación entre enfermedad y falta de recursos para su curación.

Hay enfermedades y con lo poco que tenemos no nos alcanza, y nos recetan muchas medicinas caras y ahí queda nuestra deuda y entonces tenemos que trabajar para pagar ese dinero. Los viajes, ahorita como le digo, un viaje lo quieren bien carísimo y por eso hay deudas por enfermedades. No tenemos dinero —idónde pues? - y tenemos que prestar y la cuenta aumenta (...) A veces con vecino porque cuando un hermano tiene nos puede ayudar, pero a veces con gente particular nos presta el dinero (...) Tenemos 
que salir a trabajar y tenemos que ver cómo porque es responsabilidad pagar ese dinero.

Son enfermedades que tienen que ver con los riesgos de vivir en medios insalubres y sin los suficientes recursos económicos y sociales para combatirlas. Algunas mujeres son conscientes de su situación de aislamiento y olvido, y los efectos que la falta de atención provoca en su salud personal y la de sus familiares. Como un ejemplo muy acertado tenemos el siguiente testimonio:

Sí, nosotros vamos con el doctor y decimos: "me duele la cabeza”; pero si tengo también calentura y tengo otros síntomas y no los vamos a decir, me va a dar un algo para que me quite el dolor de cabeza, pero la enfermedad en sí no es esa. La calentura es alerta de otras enfermedades, decimos nada más "tengo calentura" y me van a dar paracetamol, pero la enfermedad grave sigue estando.

En síntesis, medicinas, enfermedades y tratamientos que se diagnostican como individuales sin erradicar el problema que las causa, porque el medio físico, el agua contaminada y la carestía siguen existiendo.

\section{La asistencia sanitaria institucional}

Los pocos recursos sanitarios en las zonas rurales se traducen en pequeños ambulatorios que poseen algunas localidades que se encargan de poner inyecciones, curar heridas y atender algunos accidentes urgentes y sin grandes complicaciones, pero en donde a veces no hay ni alcohol para curar las heridas. No suelen ser centros muy concurridos, porque para casos sin grandes complicaciones se prefiere utilizar remedios caseros con hierbas medicinales que se utilizan para curar heridas pequeñas, catarros y dolores leves. Algunas mujeres han aprendido a poner inyecciones, a sanar heridas y a utilizar medicinas naturales como hierbas, ungüentos o cremas, y cobran cincuenta centavos, un peso, o la voluntad que pueda pagar la gente:

Por la misma necesidad, porque no sabíamos cómo tratar una diarrea, una gripe, cuando tenían temperatura, pues no sabíamos nada, ni cómo preparar un té. Entonces de esa misma necesidad tuvimos que ver cómo íbamos a hacerle, aunque ahorita no sabemos bien al cien por cien, pero cuando menos ya sabemos cómo prevenir unas enfermedades.

Pero, en caso de una enfermad más grave o urgente, la única solución es acudir al doctor, lo que implica gasto en dinero y también en tiempo, porque las vías de trasporte son tan deficientes que muchas veces hay que ir a pie hasta llegar a un lugar comunicado y así poder llegar hasta un centro sanitario mejor equipado. Son espacios aislados que se convierten en un infierno cuando alguien cae enfermo: "Aquí hay alguien que se enferma ya sabe que se tiene que ir rápido porque no hay ningún doctor, aquí ni clínica, y se puede uno morir más luego. No, aquí si está jodido, está muy lejos hasta acá abajo".

Una de las mayores quejas entre las mujeres es la deficiente atención sanitaria que aparece también en los hospitales de las ciudades de El Porvenir, Motozintla o Siltepec, y otros centros de salud en algunas localidades. ${ }^{20}$ Se quejan de la mala atención y de la falta de provisiones en medicinas, alcohol y otros utensilios sanitarios. A la falta de personal especializado e insuficientes suministros se une una atención individual y anónima, en la que no existen registros ni historiales de pacientes, y en la que no se tiene en cuenta las opiniones personales del enfermo. Esta atención despersonalizada se agrava en el caso de las urgencias y en las enfermedades que requieren una hospitalización. En la Sierra tener una urgencia médica implica convertirse en un número que espera a ser llamado para ser atendido y acoplarse a un sistema burocratizado que atiende casos aislados que 
pueden ser canalizados a otros centros médicos si son demasiado complicados para ser atendidos en la región. Así los enfermos viajan de un lado a otro, son enviados de Motozintla a Huitxla, a Comitán o Tapachula, y, en casos muy urgentes, a la capital Tuxtla Gutiérrez. Los viajes y las esperas complican las atenciones de los enfermos y sus posibles curaciones. Las mujeres cuentan que en urgencias es frecuente encontrar un servicio asistencial transitorio, que receta pastillas para el dolor o suero para la debilidad, las intervenciones hospitalarias, como operaciones y cirugías más complicadas, se posponen o se trasladan a otros centros, $y$, de esta forma, se acumulan historias de personas mal atendidas, de muertes incluso provocadas por las incompetencias médicas. ${ }^{21}$

No hay médicos, hay unidades de salud que son las clínicas rurales, pero nada más están enfermeras, según ellas les llaman asistentes o doctoras. Pero no es ninguna doctora, porque algunas están capacitadas para hacer algunas costuras o curaciones, y algunas no. Entonces lo que hacen es canalizarnos a Motozintla y si estamos graves, tampoco hay médicos. Ahora si que, desangrando demasiado, a Huixtla, a Tapachula. Ahora está el famoso hospital de Ciudad de Salud de Tapachula. Ahí está el paciente, nomás lo están poniendo suero y ahí sigue el paciente con su dolor, lo van a atender hasta los 3, 4 días. Dicen que si ingresan diez salen seis o cinco muertos. Hace poco, dice un señor que fue bien sano, que tenía nada más una infección de la próstata, y por falta de conocimiento le abrieron todo el pene, le rompieron la vejiga... y sólo próstata.

Lo que ejemplifican estos testimonios es el poco valor que se concede al cuerpo y a las enfermedades que padecen los pobres. Quienes tienen más posibilidades económicas pueden acudir a médicos y hospitales privados, acceder a operaciones rápidas y a medicamentos adecuados, mientras los pobres se conforman con instituciones públicas con sistemas de urgencias de mala atención y horas de espera que convierten el mal curable en incurable. El cuerpo del pobre tiene tan poco valor que se debe conformar con que le extirpen órganos como si fueran reemplazables, o ser asistido en operaciones con errores irreparables. Se habla de la falta de personal médico y de suministros, pero también de fallos e incompetencias médicas que reflejan el escaso gasto sanitario público invertido en la región y la desigualdad de acceso a una mejor asistencia sanitaria. Por eso, es normal que muchas mujeres tengan miedo de acudir a las instituciones y vean a los médicos como los mensajeros de una muerte que en muchos casos puede ser evitada.

\section{El programa Oportunidades}

Oportunidades es el programa asistencial del gobierno que tiene la mayor cobertura en la región. Pertenece a la Secretaría de Desarrollo Social (SEDESOL) y empezó a funcionar en el año 1997 con el nombre de Programa de Educación, Salud y Alimentación (PROGRESA). Actualmente brinda apoyo monetario a familias en condiciones de extrema pobreza para aumentar el ingreso familiar, contribuir a una mejor alimentación, ofrecer becas y útiles escolares para niños en edad escolar y proponer servicios gratuitos de atención sanitaria para toda la familia. Se trata de un programa de asistencia con enfoque de género, porque las mujeres se convierten en las depositarias de los recursos monetarios que deben administrar entre alimentos, educación y otros gastos necesarios. Las mujeres son también las principales destinatarias de los programas de salud; asisten a sesiones de prevención en salud reproductiva con la intención de planificar el número de hijos, reducir el riesgo de contraer enfermedades y disminuir el riesgo del cáncer cervicouterino. Reciben también una atención y control del embarazo y parto para evitar los riesgos de muerte materna, y un control de la salud y el peso de los recién nacidos. Otras sesiones 
se orientan al autocuidado y prevención de la salud familiar, con cursos de nutrición y equilibrio dietético para ofrecer una mejor alimentación familiar. Además, se imparten talleres a las mujeres sobre temas de igualdad de género, violencia doméstica, alcoholismo y drogadicción.

En la Sierra el programa tiene una cobertura amplia en todos los municipios, especialmente en las zonas rurales con altos índices de pobreza, aunque estas ayudas sólo representan 5.7\% sobre el total que se ofrece a todo el estado de Chiapas. Los recursos monetarios se reciben cada dos meses y, aunque no son cantidades muy elevadas, permiten comprar alimentos, uniformes, zapatos y utensilios escolares, sirven para las cooperaciones comunales y también para las medicinas necesarias cuando alguien se enferma. El dinero de Oportunidades está pensado como un complemento al ingreso familiar, pero en la Sierra se convierte en el único sustento seguro y se transforma en imprescindible para la subsistencia diaria. ${ }^{22}$ Por eso, no es extraño que la cobertura asistencial para muchas mujeres sea como una bendición que cae del cielo, y que algunos testimonios sean concluyentes con los efectos que esta ayuda ha tenido en sus vidas:

Yo creo que antes sufríamos más, pero gracias al programa Oportunidades que nos dan, aunque sea dos meses, compramos nuestras cosas: frutas, carnitas, leche. A veces guardamos algo y con eso compramos azúcar o lo que vaya saliendo. Eso sí mucho nos ha ayudado, pero pues ya que terminan los dos meses nos quedamos otra vez sin nada, sólo esperando, porque nuestros maridos sólo trabajan en el campo, cosechan maíz, frijol, y nada más con eso la andamos pasando.

Como beneficiarias y administradoras de los recursos monetarios, las mujeres se ven obligadas a cumplir con una serie de requisitos si quieren conservar el subsidio, como encargarse de los desayunos escolares, recoger la basura de sus localidades y acudir obligatoriamente a talleres y cursos sobre salud y alimentación. Algunas mujeres consideran que estas obligaciones les quitan tiempo para realizar otras tareas, pero también reconocen que amplían sus conocimientos y relaciones y, sobre todo, son conscientes de que la ayuda les permite seguir subsistiendo, por lo que ven al gobierno como protector de los pobres al que se le debe corresponder con obligaciones y trabajos complementarios:
Ahora dicen que es "papá gobierno"; sí, el "papá gobierno" dicen, pues sí, porque casi por él, bastante ayuda ha sido este apoyo. Ahora sí que muy a gusto, aunque si es pesado en todos los requisitos que pide el programa, pero ahí lo tenemos que aventar: sacar basura, pláticas, tenemos que ir a las justas, talleres, todo eso, pero sí, como les digo a varias compañera: yo me gusta salir, eso nos sirve de diversión para divertirnos un momento, para distraernos.

No obstante, hay otras mujeres que consideran que estas ayudas temporales no solucionan la situación de pobreza y dicen que las remesas de los migrantes contribuyen más a sustentar a la familia que los escasos recursos del gobierno que no permiten pensar en soluciones alternativas. ${ }^{23}$ Piensan que Oportunidades es una "apariencia política" para cumplir con requisitos sociales, y contribuye a una dependencia monetaria en la que la familia se acostumbra a un dinero que llega cada mes y ya no se arriesga a invertir en otros proyectos productivos. Además, para mejorar la salud es necesario tener instalaciones adecuadas que, como hemos visto, en la Sierra son deficientes o inexistentes, sin personal médico ni suministro de medicinas. Muchas de las pruebas médicas se realizan sin el consentimiento de las mujeres y, en la mayoría de los casos, no reciben los resultados ni el seguimiento adecuado. Las mujeres tienen que asistir a citas médicas en donde se les recomienda una planificación familiar y es obligatorio acudir al médico cada mes para que revise el peso de sus hijos. Así, la alimentación y la salud familiar recaen 
totalmente bajo la responsabilidad de la mujer, que con la escasa ayuda recibida debe comprar y cocinar una alimentación variada y rica en nutrientes. Estas repercusiones en el ámbito de la salud son las que más preocupan a las mujeres:

Sí, porque aquí, por ejemplo en las clínicas, las mujeres con estos programa de Oportunidades van y les hacen el papanicolau, pero no es un papanicolau competente que diga "isabes qué?, tú tienes dos cruces, tres cruces de infección, y este es tu tratamiento". Todo el resultado es porque sí están enfermas y si no les avisó nada es porque están buenas. Imagínese. No lo dan el resultado. ¿Cómo va a saber la mujer si está buena o no? De repente la mujer salió con cáncer, con un papiloma o con un tumor de ovarios.

Se le tiene que llevar a pesar a todos los niños, que con la beca que se les dan tienen que subir de peso los niños. ¿Pero cómo va alcanzar 700 pesos para nutrir a un niño? No da. Entonces, ique consumimos nosotros? Los frijoles, las tortillas, el arroz, el azúcar, pura energía. No hay vitaminas como proteínas, minerales, no lo hay. Entonces, icómo cree la enfermera que van a subir de peso esos niños? Pues no, porque el alimento es muy raquítico.

Ahorita sí las mujeres ya tiene varios hijos y si llegan embarazadas las regañan todavía a las pobres mujeres: que "imira cómo vienes, con tu grande panzona! ¿Que no te da vergüenza?; itodavía lo vas a tener? Ya tus hijos están grandes, ique bárbara!". Las enfermeras, ellas no tienen derecho, nosotras podemos decidir a qué hora queremos tener.

De hecho, el programa refuerza un rol de las mujeres como madres y amas de casa que ahora multiplican sus tareas y se responsabilizan de la nutrición familiar, de la educación de sus hijos y de la salud de toda la familia. El recurso de Oportunidades está pensado como un complemento de los ingresos y como un medio de empoderamiento de las mujeres, pero en la Sierra los ingresos son escasos, las mujeres trabajan dentro y fuera de casa, y ahora deben también asumir tareas comunitarias adicionales, independientemente de las familiares. Además, los beneficios sociales del programa no se cumplen en esta región y no garantizan que se conviertan a largo plazo en instrumentos para combatir la desigualdad social; a los pobres se les da dinero para comer, pero no para que solucionen la crisis de producción agrícola, se les ofrece una atención sanitaria deficiente que contribuye a la reproducción de la enfermedad de la pobreza, y se espera que adquieran una capacitación escolar para entrar en un mercado laboral altamente competitivo. En cualquier caso, el programa no toca el fondo del asunto porque no resuelve el origen de los ingresos ni plantea alternativas para solucionar la pobreza, sino que asiste a la población sólo el tiempo que se otorga la ayuda y reproduce así una economía permanentemente precaria.

\section{Los partos a domicilio}

En la Sierra, la maternidad y la fertilidad ilimitada se demuestra con la gestación de muchos hijos. El embarazo es un estado natural de la mujer, los partos se suceden uno tras otro, y se cuenta el número de hijos con la satisfacción de haber podido llevar a buen término el embarazo, la lactancia y la crianza. Las mujeres "quedadas", madres solteras o incluso abandonadas por un hombre, son motivo de burla y desprestigio, porque no sólo es importante tener muchos hijos sino también tener un nombre paterno para transmitirlo al hijo. Del mismo modo, la etapa más temida por las mujeres es la menopausia, pues implica el definitivo final de la etapa reproductiva. Algunas mujeres opinan que los anticonceptivos son antinaturales y se cuentan mitos e historias de otras mujeres que han sufrido enfermedades por su consumo, acaban teniendo cáncer o ya no pueden cumplir con las obligaciones sexuales para con su marido. Algunos discursos asumidos plantean 
estas fronteras simbólicas que se construyen entre mujeres que cumplen o transgreden normas femeninas asignadas socialmente. Son discursos contextuales que ofrecen protagonismo a las mujeres en los ámbitos reproductivos y familiares, y merman su participación en otras esferas sociales. El papel de esposa y madre se antepone al de otro tipo de participación social de protagonismo masculino, y ello se vislumbra en el ámbito reproductor, considerado como femenino y doméstico, y en embarazos y partos continuos que ponen en riesgo sus vidas.

En las zonas rurales de la Sierra no existen centros sanitarios especializados en la salud reproductiva y sexual de la mujer. Es necesario acudir a las cabeceras municipales, como Motozintla, que alberga el hospital más grande la región, atiende partos y complicaciones, así como otras urgencias médicas. Pero lo normal es que los partos sean atendidos en casas particulares, con la ayuda familiar o de alguna partera, y con enormes dificultades para que sobrevivan la madre y el recién nacido en caso de riesgo: "Pues nosotras [parimos] aquí en nuestra casa. Yo sólo tuve mi primer niña, no necesité partera, así nada más, yo sola, con mi esposo nada más, y mi suegra". ${ }^{24}$ Las parteras suelen trabajar por su propia cuenta, independientemente de las instituciones médicas, aunque hay casos en donde los centros de salud incorporan el trabajo de las parteras para poder llegar a mujeres que viven en localidades alejadas y así poder canalizar los posibles casos de riesgo. ${ }^{25}$ Cobran alrededor de 500 pesos si es niño y 250 si es niña, aunque se suelen rebajar los precios si las familias no pueden pagar estas cantidades. ${ }^{26}$ La diferencia de precio entre un niño y una niña se justifica por el valor superior que tiene el hombre en las familias: los niños recibirán la herencia del padre, colaboran con el padre en el trabajo agrícola, y se espera que se encarguen de la manutención en la vejez de sus progenitores. Al contrario, las niñas ayudan en las tareas del hogar sin tanto valor social y, al casarse, pasan a formar parte de la familia del marido, aunque nunca consiguen tener un control absoluto sobre importantes decisiones familiares, ni acceden a otros espacios sociales fuera del ámbito doméstico. Es el caso de las decisiones que tienen que ver con el traslado rápido de la mujer con complicaciones de parto, que dependen en muchos casos de decisiones familiares y de los recursos disponibles para el viaje.

Las historias personales de estas mujeres se supeditan al cuidado familiar y priorizan los intereses de su esposo e hijos sobre los suyos. Suelen contar sus propias historias de vida a través de los partos que han tenido, y los sucesos más importantes a través de las hazañas que consiguen sus hijos. Estas historias se combinan para relatar una vida dedicada a la reproducción familiar que repercute en la salud femenina, porque los embarazos continuos se combinan con la desnutrición, la anemia y otras enfermedades asociadas a la escasez, la debilidad y a la fatiga física. Para estas mujeres, el ámbito doméstico tiene múltiples funciones y se convierte en el lugar de trabajo, de crianza y socialización de los hijos, de relaciones conyugales y también de nacimientos y muertes, porque los partos en el domicilio tienen un mayor riesgo, y muchas veces un traslado urgente ya no es suficiente para poder salvar la vida de la madre y el hijo.

\section{Las muertes sin sentido}

Según las instituciones sanitarias, las complicaciones en el embarazo y parto, como tensión alta o preclampsia, hemorragias internas durante el embarazo y otras complicaciones, como abortos, partos prematuros, placenta previa con distintas patologías e infecciones en la etapa posterior del parto, son los diagnósticos principales que provocan índices elevados de mortalidad materna en la región. Las mujeres también sufren infecciones urinarias y vaginales o del virus del papiloma humano y desarrollan fácilmente distintos tipos de cáncer del sistema reproductivo. Por su parte, la mortalidad infantil se asocia a complicaciones después 
del parto (mortalidad perinatal), a la desnutrición, a diarreas e infecciones agudas y a enfermedades respiratorias. Muchas de estas muertes se registran y diagnostican cuando los pacientes llegan a los hospitales, pero hay otras muertes que no quedan igualmente inscritas, porque los enfermos no llegan a tiempo para salvar sus vidas. Son las muertes sin sentido, invisibles y ocultas, reflejo de la pobreza, marginación y desigualdad social de los grupos más vulnerables, y que no cuentan lo suficiente para ser registradas en las estadísticas estatales. ${ }^{27}$

Para el caso de la mortalidad materna, hay discrepancias entre las atenciones que reciben las mujeres y las que ofrecen los hospitales. Algunos testimonios conseguidos en las instituciones comentan que las mujeres no acuden a los centros médicos por su cultura y porque no están acostumbradas a revisiones médicas durante el embarazo, aunque sí es cierto que hay otras opiniones médicas que argumentan que la falta de recursos y el aislamiento geográfico son los principales inconvenientes para evitar los fallecimientos. Por su parte, las mujeres hablan de constantes preocupaciones en torno a su salud reproductiva, sobre posibles enfermedades asociadas y sobre los límites asistenciales de la región:

En Motozintla se mueren tantos niños. No tiene ni un mes que se fue una muchachita que era su primera vez de criatura que iba a tener. No sé si era de Buenavista, pero llegó ahí, ya casi con la cabecita del bebé por fuera. No la pudieron atender, que porque estaba muy estrecha, quién sabe, que necesitaban hacerle cesárea. Pero no le hace, ni cómo que la mandaron a Huixtla, y en Huixtla no hay cupos, no hay camas, y vámonos pa'trás, otra vez para Motozintla. Imagínese nada más esta situación. Da escalofríos de pensar ponerse uno en su lugar de esa pobre mujer.

Las mujeres pobres protestan por el maltrato que reciben y por tener que aguantar dolores innecesarios.
El traslado implica correr un riesgo inútil ante la deficiente atención médica, por lo que, en caso de parto, enfermedad o accidente, en muchos casos prefieren quedarse en casa, junto a los suyos, sin tanto gasto ni complicaciones. Además, la urgencia se convierte en un camino de penitencia con múltiples obstáculos:
Se tiene que sacar como sea, aunque acá así como está ahorita el paso se tapa. Entonces el año pasado o hace dos años aquí se inundó una parte y había una muchacha que tenía trabajo de parto y cómo la sacaron cargando para Lázaro. Aquí por Lázaro salieron al desvío de Comalapa, y ya ahí agarraron carro. Pero la tuvieron que sacar cargando; ya había tardado dos días con trabajo de parto, pero es que no había paso. Sufrió.

Las mujeres rurales de la Sierra se mueven entre prácticas cotidianas e instituciones médicas. Alegan un olvido institucional, que provoca que no sepan realmente qué enfermedades tienen y qué complicaciones pueden acarrearles tantos embarazos. Se preguntan por qué ahora hay tantas complicaciones en los partos y lo comparan con épocas anteriores sin tantas muertes aunque se trata de un olvido subjetivo que recuerda un pasado inexistente ante el triste presente. No tienen una respuesta adecuada ante la falta de recursos económicos y sociales que les impide acceder a un buen médico y comprar las medicinas necesarias, aunque tampoco se preguntan por qué son ellas las últimas en cuidar su salud y asumir tanta carga familiar. Prefieren ofrecer la escasa comida a sus hijos porque los niños mal alimentados son más propensos a sufrir enfermedades, y consideran que es importante que suban de peso y que tengan fortaleza. Por eso, cuando aparecen diarreas, infecciones o gripes entre sus hijos, las madres utilizan todo tipo de recursos para conseguir su curación entre hierbas y medicinas, o buscan apoyos estatales de papillas, leche o vitaminas. La enfermedad de un niño se vive con preocupación, pero la muerte de un infante 
con horror y se culpa al medio, a la falta de recursos y a las instituciones:

Yo sufrí mucho con mi hijo de trece años y se murió, nunca llegó a pesar más que siete kilos. No tomaba su leche; ¿dónde se van a curar? Hasta más delgada quedé: pesaba sesenta kilos, ahora sólo cincuenta. Perdí diez kilos, y ya después me quedé con mareos, tanto desvelar, y tenía yo que estar con la leche diaria, con harina diaria, y luego comprando pastilla para el ataque. De un apoyo nada, no me dieron ni un pesito. El municipal tomó varias fotos de mi hijito y no me dio ni un peso. Hubo uno fiesta de los inválidos, mataron dos toros, harta comida había, y sólo nos tomaron fotos y no nos mandaron nada.

Todas estas muertes innecesarias derivan de un contexto caracterizado por la privación económica y la inatención estatal. La privación se somatiza en males corporales que tienen que ver con la falta de recursos económicos y sociales, se refleja en curaciones y remedios caseros, en una ilógica dependencia a medicamentos poco efectivos, y en respuestas inmediatas pero ineficaces ante el peligro de perder la vida. Son los recursos que utilizan los pobres, que actúan por solución más que por prevención, y que acuden a un centro médico para remediar las complicaciones que involucran vivir en espacios olvidados y aislados, sólo que en muchos casos sus consecuencias son mortales.

\section{La reproducción de la pobreza}

Este trabajo ha indagado en lo que significa enfermar y morir en un entorno de marginación y pobreza extrema, entre una población rural que no tiene ni los recursos suficientes para combatir la enfermedad, ni las instalaciones adecuadas para ser atendida. Los testimonios de las mujeres nos acercan a una vida cotidiana precaria, con grandes riesgos en la salud, dentro de una intensa pobreza asociada a la tierra desgastada, a los escasos ingresos, a la incapacidad de encontrar trabajo, o a la necesaria restricción del consumo, y todo ello dentro de un ambiente familiar en donde las desgracias de la pobreza se unen a males físicos reiterativos. La población rural de la Sierra vive en un contexto de desigualdad social que les provoca serios problemas de salud, pero estos problemas no se relacionan con las condiciones ambientales, como muchas mujeres afirman, sino con vivir en contextos de exclusión social con grandes dificultades para acceder a servicios básicos, a información, a una asistencia médica y a una posible curación. Las mujeres identifican los males físicos pero no sociales, y atribuyen las enfermedades a un medio físico adverso: a las heladas y al frío de la montaña, a la contaminación ambiental de los ríos, de la tierra y los alimentos, o bien a los nuevos hábitos alimentarios que provienen de fuera. Su respuesta es contextual, dentro de una situación de escasez que se refleja en trastornos físicos que se naturalizan y terminan por convertirse en rutinarios para quienes los padecen. La naturalización de la enfermedad implica vivir en un entorno en donde los peligros se atribuyen a una serie de condiciones adversas que no pueden ser evitadas y se vuelven cotidianas, redundando en explicaciones sobre un lugar difícil que padece continuas heladas y lluvias torrenciales, y que además es un centro neurálgico para el paso de huracanes, uno de los mayores males naturales para los pobres.

Muchas de las enfermedades aquí comentadas no son atribuidas únicamente a los pobres, pero sí lo es su incidencia y reiteración por las condiciones sociales y económicas en las que viven. No se ha pretendido hablar de enfermedades graves que se diagnostican y no tienen rápida solución, sino de contextualizar males físicos que reflejan carencias sociales, es decir, de una enfermedad de la pobreza que adquiere características de desigualdad y se convierte en rutinaria para quienes la padecen. Por eso, si los niños se enferman de gripe, diarreas o infecciones más graves, 
es porque los alimentos en mal estado, las viviendas mal acondicionadas, las aguas estancadas y heladas, o la desnutrición por las carencias alimentarias, hacen mella en sus cuerpos, mientras los adultos acumulan una debilidad y malnutrición que deriva en problemas mayores. En cierta forma, es mucho más fácil dar alguna explicación de los males a causas externas que asumir una situación de olvido institucional. Así, la pobreza no es la principal causa sino la consecuencia de que los enfermos no se curen, porque no se pueden comprar medicinas o realizar un traslado en caso de urgencia. Por otro lado, sí es la causa mayor de la mala nutrición familiar, porque imposibilita comprar los alimentos necesarios para comer e impide vivir con tranquilidad de cara al futuro. Por eso muchos hijos deciden marcharse y traspasar la frontera hacia Estados Unidos, para conseguir trabajo, dinero para subsistir y olvidarse de este callejón sin salida.

Resulta paradójico pensar cómouna población que se dedica a la producción agrícola sea la de mayor carencia en alimentación. En la Sierra, la población no se muere de hambre, pero sí de complicaciones que provocan una mala alimentación, como la desnutrición, infecciones estomacales y diarreas, que son causas importantes de mortalidad infantil; la misma mala alimentación provoca anemia entre mujeres y complicación en sus embarazos $y$ otros graves efectos secundarios entre infantes y adultos. La escasez en alimentos y otros enseres es un claro ejemplo del impacto que la crisis actual tiene en la vida cotidiana de las familias campesinas. Ahora se come menos y con una limitada variedad de productos entre maíz, frijol, papas, arroz o pasta, que no alimentan pero sí llenan el estómago. Las mujeres dicen que la escasez provoca preocupaciones constantes y sufrimiento, y que deben buscar recursos donde sea. Su situación ha empeorado, con doble o triple carga de trabajo para ellas, siempre buscando salidas para enfrentar la crisis en programas de asistencia que no son suficientes, vendiendo productos agrícolas o alimentos preparados que ya nadie compra, o pidiendo préstamos y contrayendo deudas. La pobreza se ha agudizado y ha hecho mella en grupos domésticos que ya no tienen las mismas capacidades para enfrentar la supervivencia. Algunos estudios recientes nos han alertado de este desgaste de los recursos familiares ante el impacto de la crisis actual, de ayudas sociales deterioradas que se reducen en situaciones de miseria y provocan un mayor aislamiento (González de la Rocha, 2005).

Para muchas mujeres, las medicinas son una pócima mágica que pueden paliar las desgracias, curar trastornos físicos y entrar en ese mundo de cuidados médicos y de consejos adecuados para su salud. Pero el personal médico receta tratamientos que se atribuyen también a causas individuales e invisibiliza los males sociales de la desigualdad. Las enfermedades reiterativas son asociadas por ellos con descuidos o con una cultura rural y atrasada, cuando en realidad son causa y consecuencia de una política excluyente, que a la vez que impide la curación, permite que los pobres entren en un proceso de medicalización constante del cuerpo (Menéndez, 2005b; Scheper-Hughes, 1997). Por eso, otro de los temas claves de la enfermedad de la pobreza es la constante dependencia en medicamentos y en largos tratamientos que no pueden ser solventados y que reproducen una situación de continua escasez. La enfermedad de la pobreza se encuentra en un círculo sin salida, porque surge de un contexto de exclusión y se reproduce en la misma privación. En la Sierra, los pobres son medicados con una gran variedad de productos medicinales, pastillas de marcas diferentes, inyecciones o ampolletas, y, quizás por eso, en la cabecera de Motozintla se encuentran tantas farmacias, alrededor de una en cada esquina, siempre repletas de gente esperando el turno para comprar su "receta mágica".

$\mathrm{Y}$, sin embargo, otra de las paradojas es la deficiente asistencia sanitaria de la región, que se sabe existe porque mucha gente comenta que tiene que comprar continuamente medicinas para paliar dolores físicos, o porque en la capital hay una larga cola de gente que espera en los hospitales y centros de salud para ser 
atendida. Ante el olvido institucional en el mundo rural, las mujeres intentan sustituir las carencias sanitarias con sus propios esfuerzos: aprenden a poner inyecciones, se convierten en ayudantes de parteras, se informan sobre las plantas adecuadas o hacen pomadas para curar catarros y paliar dolores. Y cuando bajan a Motozintla, acuden al mercado a abastecerse de otros productos que también pueden ser eficaces: productos curativos demarcas desconocidas, cremas envasadas, ungüentos que sirven para las manchas de la cara y el cuerpo, bebidas "milagrosas" que curan la gastritis, que se consumen para enfrentar problemas cotidianos y sustituyen a las recetadas por las instituciones médicas, que son insuficientes para curar los males. Son productos que se comercializan como "milagrosos" y se convierten en indispensables dentro de una economía escasa que reproduce continuamente enfermedades que requieren de todos los medios para poder ser erradicadas.

Pero estos males son difíciles de eliminar y, aunque se buscan todo tipo de recursos, resultan ser soluciones pasajeras ante un entorno mísero en donde la pobreza, la marginación y la enfermedad se alimentan mutuamente. La pobreza se reproduce continuamente en la falta de trabajo y capacitación escolar, en los escasos ingresos y en la imposibilidad de salir de esta situación. Se acompaña de la marginación y el aislamiento social con falta de instalaciones adecuadas en las viviendas, en escuelas, en centros de salud, en trasportes o en comunicaciones. La pobreza impide invertir en la producción agrícola y la marginación agudiza el aislamiento, sin inversión adecuada en proyectos productivos, en tecnología o en redes de comercio eficaces. La pobreza provoca escasez alimentaria e incapacidad de adquirir otros suministros para el consumo diario. Y así llegamos al ámbito de la salud-enfermedad en un contexto propicio para su constante reproducción, con cuerpos mal alimentados, enfermedades sin curación, con deudas acumuladas, dependencia de medicinas ineficaces, casos de urgencia mal atendidos, que provocan entrar en el círculo sin salida de constante privación, debilidad y malnutrición.

Las muertes sin sentido también reproducen la desigualdad, con riesgos individuales que se convierten en rutinarios y con problema que tienen que ver con la falta de posibilidades contextuales para solucionarlos. Se percibe esta normalización en la situación de riesgo cuandolas madrescuentan que es "normal" tener muchos hijos y perder algunos por el camino, o correr peligros innecesarios en el parto porque los recursos no dan para más. Es aquí donde la desigualdad adquiere matices de género y generación y en donde se reproducen prácticas y significados desiguales por el hecho ser mujer o haber nacido niña. Son situaciones críticas que reflejan una violencia estructural relacionada con la pobreza y la falta de asistencia sanitaria, pero también con el desigual valor que se concede a la vida y salud de las mujeres. De esta forma, su salud dañada se carga invisiblemente para que el resto pueda seguir la dinámica diaria, y tengan todos un plato de comida, la ropa lavada o la casa limpia. Los embarazos continuos, los partos de riesgo, las enfermedades del aparato reproductor como infecciones y cáncer de ovarios, son asuntos que involucran y dependen de las mujeres. El riesgo también es individual y las causas se relacionan con conductas adecuadas o inapropiadas que se significan entre obligaciones sexuales, malos hábitos, consumo de medicamentos que impiden los embarazos, o de cuerpos demasiado gastados para cumplir su función reproductora. Las mujeres tienen más riesgos de contraer enfermedades porque sencillamente son mujeres que asumen trabajo, cuidados, responsabilidades y obligaciones, y cuando su cuerpo habla para expresar sus límites, a veces ya es demasiado tarde.

Por eso, el mundo de la población sin recursos, en su mayoría analfabeta, que vive en un medio rural sin posibilidad de un traslado rápido, la que soporta el frío y las heladas sin las instalaciones adecuadas, que agota su cuerpo en horas de trabajo al aire libre, o que come de lo poco que da la tierra, ese es el mundo que reproduce constantemente trastornos físicos y somatiza 
carencias sociales. Los pobres deben conformarse con acudir a centros anónimos y ser tratados sin nombre, sin revisiones previas, ni derivación a especialistas. Temen enfermar o ir al hospital porque saben que allá su cuerpo no es más que eso: un cuerpo marginado al que le han privado de sus necesidades, que aguanta tratamientos y dolores, y entra en un sistema burocrático de esperas, traslados y errores médicos. Un cuerpo bien alimentado y atendido no expresa tantas protestas, pero el de los pobres se convierte en el último recurso para expresar malestar y disconformidad ante un entorno de exclusión social. Un cuerpo, en fin, que protesta y termina por convertirse en un enfermo crónico, en un individuo fragmentado, o en un ser anónimo que pierde la vida en su camino por reclamar justicia.

\section{Notas}

${ }^{1}$ Chiapas, junto a Guerrero y Oaxaca, son los tres estados que presentan los índices más elevados de pobreza y rezago social de todo el país. Según estadísticas de CONEVAL, en Chiapas en el año 2008 la población en situación de pobreza multidimensional asciende a $76.7 \%$ con indicadores de rezago educativo, bajos ingresos, carencia alimentaria, escasos servicios básicos en la vivienda, y limitado acceso a los servicios de salud. En este último indicador, las cifras han oscilado entre 81.6\% de la población sin acceso médico en el año 2000 para pasar a 43.2\% en el año 2010 (CONEVAL, 2008, 2010).

${ }^{2}$ En el año 2005, los municipios que presentan muy alta marginación son Siltepec, Bejucal de Ocampo y El Porvenir. El resto de municipios presentan alta marginación en este orden: La Grandeza, Bella Vista, Amatenango de la Frontera, Mazapa de Madero y la cabecera municipal de Motozintla (CONAPO, 2005).

3 La Sierra ha sufrido dos huracanes importantes, el Mitch en el año 1998 y el Stan en el 2005. Con el huracán Mitch, las pérdidas fueron elevadas, pero el Stan fue de dimensiones mayores y fue considerado como uno de los mayores desastres naturales que había azotado al estado de Chiapas con consecuencias desastrosas para las regiones de la Sierra y el Soconusco.

${ }^{4}$ El Consejo Nacional de Población (CONAPO) define a la marginación como un fenómeno estructural múltiple y mide la marginación socioeconómica de la población en base a las carencias a bienes y servicios básicos en los ámbitos de educación, ingresos monetarios, vivienda y distribución de la población (CONAPO, 2000, 2005).

${ }^{5}$ Según los datos de INEGI, en el año 2000, 13.2\% de las viviendas en la región no contaban todavía con el servicio de energía eléctrica, 35.5\% no disponían de agua entubada, $44.7 \%$ tenían agua entubada fuera de la vivienda, mientras que $46.6 \%$ no disponían de drenaje (INEGI, 2000).

${ }^{6}$ La investigación sobre "Incidencia de la crisis global en la situación, condición y participación de las mujeres marginales en Chiapas", se llevó a cabo durante agosto de 2009 y julio 2010, dentro de la línea de investigación "Género y Fronteras" en el cuerpo académico "Política, Diferencia y Fronteras" del CESMECA-UNICACH, y contó con la financiación del Consejo Nacional de Ciencia y Tecnología (CONACYT) en el marco del Proyecto Integral de Formación de Recursos Humanos de Alto Nivel en Equidad de Género y Violencia contra la Mujer. El proyecto fue coordinado por las doctoras Inés Castro, Mercedes Olivera y Teresa Ramos y contó con la participación de otros seis investigadores para analizar por separado las nueve regiones que integran el estado de Chiapas. El trabajo aquí presentado se dedica a Horacio Gómez Lara, responsable de la región Selva, que murió en junio del 2011.

${ }^{7}$ En el trabajo de campo se realizaron alrededor de 60 entrevistas semi-estructuradas y se aplicó una encuesta estadísticamente representativa a 148 mujeres que habitan en localidades de alta y muy alta marginación en los ocho municipios de la región. También se realizaron entrevistas a autoridades locales en las cabeceras municipales para recabar información sobre 
la intervención estatal. Asimismo, se realizaron cuatro talleres con mujeres que forman parte de la organización Nuevo Horizonte, quienes trabajan para combatir la pobreza y erradicar la desigualdad de género. En el trabajo de campo se contó con la participación del asistente Darío Robledo Solís.

${ }^{8}$ En los datos de las encuestas, las mujeres en edad reproductiva (16 a 45 años) representaron 59\%, mientras que en edad no reproductiva (46 a 65 o más años) $41 \%$. De las cuales, 26\% contestaron que no sabían leer ni escribir, la gran mayoría mujeres mayores de 40 años, mientras que 64\% tenían nivel de primaria. Por su parte, 96\% de las mujeres contestaron que su ocupación principal era el hogar, aunque los datos de campo revelaron que muchas de ellas se dedican además a otras ocupaciones informales; preparación y venta de alimentos o lavado de ropa entre otras (encuesta: Cesmeca-Unicach, 2009-2010).

9 El 95\% de mujeres encuestadas contestaron que continuaban utilizando la leña para cocinar. Por su parte, $96 \%$ de las viviendas tenían electricidad, pero $28 \%$ no poseía todavía agua entubada, mientras que 95\% poseían letrina, $74 \%$ sin drenaje. En relación con los electrodomésticos, $62 \%$ de mujeres contestaron que poseían una radio, y sólo 54\% tenían un televisor; $66 \%$ tampoco poseía refrigerador y 14\% contestó que disponía de celular (encuesta: Cesmeca-Unicach, 20092010).

${ }^{10}$ Según los datos de la encuesta, la composición familiar de la Sierra es mayoritariamente nuclear, integrada por padres e hijos solteros. De las 148 mujeres encuestadas, se encontraron 110 familias nucleares y sólo 16 familias extensas. Por último, 7 familias compuestas sólo por la pareja, y 19 madres solteras o viudas que viven solas con sus hijos. El 45\% de matrimonios se forman por unión libre y no se legaliza formalmente la unión. Por otro lado, las familias de padres e hijos tienen un promedio entre 5 y 8 miembros, aunque pueden llegar también a estar compuestas por 10 miembros (encuesta: CesmecaUnicach, 2009-2010).
"La ocupación principal de los esposos en la región Sierra es la de campesino (91\%), mientras que el resto de ocupaciones aparece en porcentajes pequeños: artesano, jornalero, albañil, chófer, obrero de fábrica, empleado y comerciante (encuesta: Cesmeca-Unicach, 2009-2010).

${ }^{12}$ Los autores diferencian entre los conceptos de riesgo y vulnerabilidad social: si el primero hace alusión a la posibilidad de que ocurra un suceso y a las conductas que afectan de manera individual a una persona, el segundo se refiere a las condiciones estructurales de desigualdad social que provocan que las personas sean más propensas a fallecer, padecer enfermedades, contagiarse o sufrir accidentes (Brofman et al, 2001).

${ }^{13}$ Para Menéndez, el modelo medico hegemónico hace referencia al conjunto de prácticas, saberes y teorías generados históricamente por la medicina científica occidental identificada como la única forma legítima de atender la enfermedad (Menéndez, 2003, 2005b).

${ }^{14}$ Según los datos de la encuesta, la dieta familiar diaria se compone de tortillas de maíz, frijol y pozol. Otros ingredientes como algunas verduras y hortalizas (mayoritariamente tomates, y papas), los elotes, el arroz y la pasta, los huevos y el pollo se compran algunos días a la semana, mientras que la carne, las frutas, la leche y derivados se consumen un día a la semana o casi han desaparecido por completo (encuesta: CesmecaUnicach, 2009-2010).

${ }^{15}$ Chiapas ocupa el segundo lugar de desnutrición del país después de Guerrero. Según La Línea Basal de los Objetivos del Milenio del Gobierno de Chiapas y con información proporcionada por CONEVAL, en el año 2000, más de la mitad de la población de Chiapas (53,3\%) presentaba índices de pobreza alimentaria y para el año 2008 el índice se reduce a 35.4\% (CEIEJ, 2010). En el año 2007, la población infantil menor de 5 años con algún grado de desnutrición representaba 36\% del total (PNUD y IEM, 2009).

${ }^{16}$ En la encuesta se obtuvo que una familia en la Sierra gasta un promedio de $\$ 9.90$ al día para su manutención. 
17 Las autoridades entrevistadas relacionadas con instituciones sanitarias fueron las siguientes: Centro de Salud y DIF Municipal en Bella Vista, Delegación Instituto Chiapas Solidario y Hospital Regional en El Porvenir; Centro de Salud y DIF Municipal en la Grandeza; Oficina Central del Programa Oportunidades, IMSS Hospital Rural en Motozintla y Hospital Regional y DIF en Siltepec.

$18 \mathrm{La}$ oncocercosis es una enfermedad parasitaria crónica causada por un gusano y transmitida por varias especies de la mosca negra que provoca severas lesiones cutáneas y oculares. En México se encuentra el mosquito del género simolidum que se cría en los arroyos de las regiones cafetaleras (Vázquez Castellanos, 1991).

${ }^{19}$ Enlaencuestaapareció queelgastofamiliaren medicinas era elevado y, en algunos casos, doblaba incluso el gasto que se utilizaba en alimentos y otros enseres. Mientras $88 \%$ de las mujeres gastaban un promedio de $\$ 500.00$ a \$1,000.00 mensuales en alimentación, 58\% de las mujeres contestaron que gastaban mensualmente alrededor de $\$ 200.00$ a $\$ 800.00$ en medicinas, $23 \%$ hasta $\$ 3,000.00$, mientras que $4 \%$ había gastado entre $\$ 3,000.00$ y $\$ 12,000.00$ en un solo mes (encuesta: Cesmeca-Unicach 2009-2010).

${ }^{20}$ Según los datos del INEGI sobre mortalidad general, los municipios de El Porvenir, Motozintla y Siltepec concentran $80 \%$ de muertes con base en que son los tres centros que poseen los hospitales más importantes de la región y a los que acuden la gran mayoría de enfermos que han podido trasladarse de otros municipios regionales. En el año 2008, las enfermedades que provocaron una mayor mortalidad fueron en este orden: síntomas y hallazgos anormales clínicos y de laboratorio (13.7\%), enfermedades del sistema circulatorio (12.7\%), tumores (11.7\%), enfermedades del sistema digestivo (11.3\%), otras causas externas de morbilidad y mortalidad $(10.9 \%)$, enfermedades infecciosas y parasitarias (9.3\%) y enfermedades respiratorias (9.1\%) (INEGI, Estadísticas de mortalidad, 1985-2008).
${ }^{21}$ Durante mi trabajo de campo fui testigo de uno de esos casos de incompetencia médica con el accidente de un campesino que estaba cortando madera con una sierra y le entró un trozo de hierro en un ojo. Empezó a sangrar y el ambulatorio lo envió de urgencias a Motozintla. Después de tres horas de espera, lo enviaron a Tapachula (otras tres horas de viaje, más la espera para ser atendido). Cuando finalmente lo atendieron, había pasado tanto tiempo desde el accidente que el hombre perdió el ojo.

${ }^{22}$ De las 148 mujeres encuestadas, 124 recibían el subsidio de Oportunidades con una cantidad que oscilaba entre $\$ 700.00$ y $\$ 770.00$ cada dos meses. Por su parte, 53 de ellas contestaron que el dinero que recibían era el ingreso más importante para el sustento familiar.

${ }^{23}$ Los siguientes comentarios surgieron en talleres participativos con las mujeres de la organización Nuevo Horizonte que hablaron sobre las ventajas y desventajas del programa Oportunidades.

${ }^{24}$ Los datos de la encuesta revelaron que el promedio de partos entre las mujeres era de 3 y 12 hijos, mientras que el de hijos vivos era entre 3 y 8 hijos, lo que demuestra que puede existir una mortalidad fetal o infantil alta (Encuesta Cesmeca-Unicach, 2009-2010).

${ }^{25}$ Según los datos de INEGI, en el año 2008, 61.7\% de las mujeres parieron en casa y sólo 27.1\% llegaron al hospital para ser atendidas (INEGI, 2008).

${ }^{26}$ Esta información surgió en varias entrevistas a mujeres que se habían convertido en parteras que trabajaban en localidades cercanas a su residencia y poseían diferentes niveles de capitación; algunas habían aprendido a ser parteras en cursos y talleres, mientas otras habían adquirido los conocimientos dentro una tradición familiar o a través de una experiencia práctica.

${ }^{27}$ Según las estadísticas del INEGI del año 2005, mientras la tasa de mortalidad infantil de menores de un año a nivel del país es $16.8 \%$, en el estado de Chiapas era $23.9 \%$, únicamente superada por el estado de Guerrero con $24.4 \%$. En la Sierra, las causas más comunes de mortalidad infantil son las afecciones originadas en el 
periodo perinatal, que representan el $55.8 \%$ de todas las defunciones, seguidas de las infecciosas y parasitarias $(11.6 \%)$ y las enfermedades del sistema respiratorio (7\%), aunque puede existir un subregistro importante. Igual ocurre con las muertes maternas. En el año 2008, Chiapas ocupa el segundo lugar de muerte materna en el país con una razón de 96.8 muertes por cada 1,000 niños nacidos vivos, con datos estadísticos poco fiables para una zona marginal como la Sierra con una gran cantidad de partos atendidos en el domicilio familiar (INEGI, Estadísticas de mortalidad).

\section{Bibliografía}

Bronfman Mario, Patricia Uribe, David Halperin y Cristina Herrera (2001), "Mujeres al borde... vulnerabilidad a la infección por VIH en la frontera sur de México", en Esperanza Tuñón Pablos (coord.), Mujeres en las fronteras: trabajo, salud y migración (Belice, Guatemala, Estados Unidos y México), México: El Colegio de la Frontera Sur, El Colegio de Sonora, El Colegio de la Frontera Norte, y Plaza y Valdés, pp.15-31.

Comité Estatal de Información Estadística y Geografía (CEIEG), Chiapas Gobierno del Estado (2010), Línea Basal de los Objetivos de Desarrollo del Milenio para Chiapas, Tuxtla Gutiérrez: Dirección de Geografía, Estadística e Información, Subsecretaría de Planeación, Presupuesto y Egresos, Secretaría de Hacienda del Estado de Chiapas.

Consejo Estatal de Población, COESPO (2002) Diagnósticos Sociodemográficos y económicos municipales, 2000, Chiapas: Consejo estatal de Población.

Consejo Nacional de Evaluación de la Política de desarrollo social (CONEVAL) (2008), Metodología de la medición multidimensional de la pobreza. Chiapas.

Consejo Nacional de Evaluación de la Política de desarrollo social (CONEVAL) 2010, Indicadores de carencias sociales 2000-2010 http://www.coneval.gob. mx (julio 10 de 2010).
Consejo Nacional de Población, CONAPO (2000), Índices de Marginación 2000.

Consejo Nacional de Población, CONAPO (2005), Índices de Marginación 2005, http://www.conapo.gob.mx/ index.php?option=com_content\&eview $=$ article $\&$ $\&$ id $=7$ $8 \& \&$ Itemid=194, (2 de julio de 2010).

Farrona, Jesús Ruíz (2006), Avance del primer informe sobre: violencia directa, violencia estructural, violencia cultural contra las personas en situación de sin hogar en España- 2006, Barcelona: Centre d'acollida Assís.

Freyermunt, Graciela (2011), "La muerte prematura de mujeres en los Altos de Chiapas", Revista Pueblos y fronteras digital, Vol 6, núm 10, 2010-2011, http://www. pueblosyfronteras.unam.mx/al0nlo/art_06.html, (julio 10 de 2010).

Galtung, Johan (1981), "Contribución específica de la irenología al estudio de la violencia: tipologías", en J. M. Domenach, H. Laborit, A. Joxe, J. Galtung, D. Senghaas, O. Klineberg, J. D. Halloran, V. P. Shupilov, K. Poklewski-Koziell, R. Khan, P. Spitz, P. Mertens, E. Boulding, La violencia y sus causas, Paris: UNESCO, pp. 91-106.

Goldberg, Alejandro (2010), "Abordaje antropológico comparativo en torno a la incidencia del Chagas y la tuberculosis en inmigrantes bolivianos residentes en Barcelona y Buenos Aires, respectivamente", en Revista de Humanidades Médicas e Estudios Sociales de la Ciencia y la Tecnología, Vol. 1, núm 3, abril. http://www. doaj.org/doaj?func=openurl\&genre=article\& $\&$ issn=185 $24680 \&$ date $=2010 \&$ volume $=1 \&$ issue $=3 \&$ spage $=e \ddot{~} \quad(2$ de julio de 2010).

González de la Rocha, Mercedes (1986), Los recursos de la pobreza: familias de bajos ingresos de Guadalajara, Guadalajara: El Colegio de Jalisco, Ciesas y SPP.

González de la Rocha, Mercedes (2005), Espirales de desventaja; pobreza, ciclo vital y aislamiento social, Ponencia presentada en el X Congreso Internacional del CLAD sobre la Reforma del Estado y de la Administración Pública, Santiago, Chile, 18 -2l Oct. 
Instituto Nacional de Estadística, Geografía e Informática (2000), XII Censo General de Población y Vivienda, México: INEGI.

Instituto Nacional de Estadística, Geografía e Informática (2005), Conteo de Población y Vivienda, México: INEGI.

Estadísticas de mortalidad (1985-2008), México: INEGI, http://www.inegi.org.mx/, ( julio de 2010).

Lomnitz, Larissa (1975), ¿Cómo sobreviven los marginados?, México, D. F.: Siglo XXI Editores.

Menéndez, Eduardo L. (1994), "La enfermedad y la curación: ¿qué es la medicina tradicional?", en Alteridades, Vol. 4, núm 7, pp.7l-83.

Menéndez, Eduardo L. (2005a), "El modelo médico y la salud de los trabajadores", en Salud Colectiva, Vol. I, núm. 1, pp. 9-32.

Menéndez, Eduardo L. (2005b), "Intencionalidad, experiencia y función: la articulación de los saberes médicos”, en Revista de Antropología Social, núm. 14, pp. 33-69.

Programa de Naciones Unidas para el Desarrollo e Instituto Estatal de las Mujeres (PNUD y IEM) (2009), Tejiendo Igualdad. Manual de Transversalización de la perspectiva de género, México: Gobierno de México, Gobierno del estado de Chiapas, Instituto Estatal de las Mujeres, Instituto Nacional de las Mujeres.

Scheper-Hughes, Nancy (1997), La muerte sin llanto. Violencia y vida cotidiana en Brasil, Barcelona: Ariel.
Spitz, Pierre (1981), "Violencia silenciosa: hambre y desigualdades", en J. M. Domenach, H. Laborit, A. Joxe, J. Galtung, D. Senghaas, O. Klineberg, J. D. Halloran, V. P. Shupilov, K. Poklewski-Koziell, R. Khan, P. Spitz, P. Mertens, E. Boulding, La violencia y sus causas, Paris: UNESCO, pp. 217-240.

Vázquez Castellanos, José Luís (1991), "Cafeticultura e historia social de la oncocercosis en el Soconusco, estado de Chiapas, México", en Salud Pública, Vol. 33, núm. 2, pp. 124-135.

Villafuerte Solís, Daniel y María del Carmen García Aguilar (2004), "Pobreza y migración en la Sierra de Chiapas", en LiminaR. Estudios sociales y humanísticos, Año 2, vol. II, núm. 1, junio 2004, pp. 81-93.

Villafuerte Solís, Daniel y María del Carmen García Aguilar (2006), "Crisis rural y migraciones en Chiapas", en Migración y Desarrollo, núm. 6, Primer Semestre, 2006, Red Internacional de Migración y Desarrollo, (registros en trámite), Zacatecas, México, pp. 102-130.

Villafuerte Solís, Daniel y María del Carmen García Aguilar (2008), "Algunas causas de la migración internacional en Chiapas", en Economía y Sociedad, Vol. XIV, núm. 21, enero-junio, 2008, México: Universidad Michoacana de San Nicolás de Hidalgo, pp. 4l-58. 